\title{
General practice compliance study: is it worth being a personal doctor?
}

\author{
P R A ETTLINGER, G K FREEMAN
}

\begin{abstract}
While lip service is paid to the concept of the personal doctor in British general practice, little evidence is available to show that personal doctoring improves patient care. The hypothesis that close identification with a general practitioner leads to better drug compliance was therefore tested. One hundred and nineteen patients from two health centres who were prescribed an antimicrobial drug for a new episode of illness were visited at home four or five days after the prescription was given and their compliance with the prescription and identification with their doctor assessed. Compliance with the prescription was found to be strongly associated with whether the patient thought that he knew the prescribing doctor well.

It is suggested that more attention is paid to consultation technique, particularly with new patients. One way of improving compliance may be for patients to see the same general practitioner, using a personal list system. Further studies are needed for patients taking long-term treatment, especially hypotensive drugs.
\end{abstract}

\section{Introduction}

Personal care has long been central to the concept of general practice in Britain but has normally been advocated from principle rather than from evidence of its benefits. ${ }^{12}$ True personal care is declining. Since 1948 there has been a trend from single-handed to group practice, and Aylett pointed out how a group practice now often means a combined list, whereby the patients may see any partner in the practice rather than being specifically encouraged to stay with one doctor. ${ }^{3}$ Recently Gray published a strong appeal for a return to personal doctoring and described how this was being achieved in his own group practice. ${ }^{4}$ He suggested that one benefit of personal care may be improved compliance, but the study that he quoted to support his view was performed in office paediatric practice in the USA. ${ }^{5}$

When one of us arrived as a student in a modern group practice and noticed patients who were unsure of who was their doctor it seemed natural to ask whether personal doctoring really made any difference. This practice operated the combined list system; the proximity of another practice in similarly modern premises enthusiastically operating a separate, or personal list, system prompted us to test the hypothesis that close identification with a general practitioner means better drug compliance.

\section{Patients and method}

In a pilot study we reviewed the case records from all surgery sessions performed by principals in the two practices. Selected patients were visited at home several days after their consultation and inter-

Faculty of Medicine, University of Southampton

P R A ETTLINGER, final-year student

G K FREEMAN, MB, MRCP, senior lecturer in primary medical care viewed using a structured questionnaire to assess their "identification" with their doctor. At the end of the interview a pill count was performed. With the experience gained we were able to confine the main study to new prescriptions for antimicrobial drugs, this being the largest class of drugs for which specific regimens were consistently recorded.

In the main study we included four principals operating a combined list system in practice $\mathrm{A}$ and three principals with personal lists of patients in practice $B$. The patients had attended the surgeries in normal working hours.

We used five criteria for including patients in the study. (1) Patients should have been registered for at least one year and consulted the practice at least five times to allow them to get to know a doctor. (2) The prescription should be for a new antimicrobial drug though not necessarily for a new episode of illness. The medicine should be in tablet or capsular form. Dose and frequency should be specified with at least twice-daily administration for at least five days. (3) To avoid confusion no other continuing treatment should have been started in the past month. (4) Patients should be aged 16-84 years because the old and the young are less likely to be personally responsible for their compliance. (5) Patients should have no active psychiatric condition as this has been associated with poor compliance. ${ }^{6}$

One of us (PRAE) visited both practices daily for six weeks. He reviewed the case records from the previous 24 hours to select all the patients eligible for entry. He then visited these patients at home, without prior warning, after four or five days. Up to six visits were attempted by $7 \mathrm{pm}$ on the fifth day before the patient was recorded as out. At the visit the patient was interviewed using a questionnaire in which 38 questions covered three areas-namely, the medicine and compliance, factors known to affect compliance, and the patient's identification with his doctor. At the end of the interview the patient was asked to produce his medicine bottle; the label was checked for agreement with the case records and the contents counted.

After the visits had been completed (to avoid biasing the interviews) the patient's records were examined to find the number of times he had seen the prescribing doctor during the period both had been with the practice. The total of each patient's consultations in the same period was also noted.

\section{Results}

\section{POPULATION}

Complete results were obtained for 119 out of 136 patients $(88 \%)$ eligible for inclusion in the study. Of the remaining 17 patients, five were not found at all, six were not at the address known to the practice, four refused to be interviewed, and two were interviewed but their compliance could not be confirmed because of disagreement between the labels on their medicine bottles and their medical records. Forty of the 119 patients finally included were from practice $A$ and 79 from practice $B$. Unfortunately, practice $B$ had no age-sex register, but the 40 patients from practice A were typical of the practice as a whole except that male patients aged under 45 years were underrepresented.

\section{IDENTIFICATION WITH THE DOCTOR}

Patients were said to be "identifiers" if they answered yes to the question "Do you feel that you know the doctor who prescribed the tablets well ? Ninety-six patients $(81 \%)$ from the two practices were identifiers: $73(92 \%)$ from practice $\mathrm{B}$, with its personal lists, and 23 $(58 \%)$ from practice A, with a combined list. Identification was more likely if the prescribing doctor was either the doctor usually seen by that patient (table I) or the doctor of choice for that consultation, or both. 
TABLE I-Numbers of contacts of identifiers and non-identifiers with prescribing doctor

\begin{tabular}{|c|c|c|c|c|}
\hline & \multicolumn{2}{|c|}{ Practice A } & \multicolumn{2}{|c|}{ Practice B } \\
\hline & Identifiers & $\begin{array}{c}\text { Non- } \\
\text { identifiers }\end{array}$ & Identifiers & $\begin{array}{c}\text { Non- } \\
\text { identifiers }\end{array}$ \\
\hline $\begin{array}{l}\text { No of patients } \\
\text { No of contacts with } \\
\text { prescribing doctor: }\end{array}$ & 23 & 17 & 73 & 6 \\
\hline $\begin{array}{l}\text { Average No } \\
\text { Range } \\
\text { Average No as proportion } \\
\text { of all contacts with doctor } \\
(" . .)^{*}\end{array}$ & $\begin{array}{l}10 \cdot 3 \\
1-30\end{array}$ & $\begin{array}{l}1 \cdot 8 \\
1-4\end{array}$ & $\begin{array}{l}16 \cdot 4 \\
3-80\end{array}$ & $\begin{array}{l}4 \\
1-14\end{array}$ \\
\hline
\end{tabular}

*Average number of contacts with prescribing doctor expressed as a percentage of all contacts with a doctor during the period when both patient and prescribing doctor were with the practice.

\section{COMPLIANCE}

Compliance was assessed by the pill count. A compliance index expressed the number of tablets or capsules actually consumed as a percentage of the number that should have been consumed by the time of the interview. The scatter of the results suggested dividing the patients into three groups: 21 non-compliers with compliance index $0-85^{\circ}$, 38 partial compliers with compliance index $86-95^{\prime \prime}$ or $103-$ $122^{\circ} \%$, and 60 full compliers with compliance index $96-100 \%$. We thought that patients taking too much medication could not be classified as fully compliant.

The overall degree of compliance was good. A fifth of patients, however, were not complying well, and this proved to be related to non-identification; conversely, of the 60 full compliers, 55 were identifiers (table II). Clearly, identification of the patient with the

TABLE II-Identification and compliance, expressed as numbers ( $\left.{ }_{0}\right)$ of patients

\begin{tabular}{lccc}
\hline & Identifiers & Non-identifiers & All patients \\
\hline Xon-compliers & $8(8)$ & $13(57)$ & $21(18)$ \\
Partial compliers & $33(34)$ & $5(22)$ & $38(32)$ \\
I.ull compliers & $55(57)$ & $5(22)$ & $60(50)$ \\
\hline & $96(100)$ & $23(100)$ & $119(100)$ \\
\hline
\end{tabular}

$y^{*}=30 \cdot 0, p \cdot 0 \cdot 0005$

doctor and compliance with the medication were strongly associated. It follows that compliance was better in practice $B$ with its higher degree of identification than in practice $\mathrm{A}$, but even when the two practices were considered individually there was a strong association between identification and compliance, which was statistically significant even with the smaller numbers.

The remainder of the questionnaire was designed to study variables that had previously been found or suggested to affect compliance. It was important to check that these did not account for the large observed difference in compliance between identifiers and nonidentifiers. No significant association with compliance at the $5^{\circ}$ level was found for the following variables: age; sex; family state; dose and regimen; medicine thought to be helpful; frequency of seeing doctor; time interval to interview; patient's own rating of normal health; perceived severity of illness; pain at presentation or interview; svmptomatic improvement; staying in bed; and staying indoors.

\section{Discussion}

These results strongly support our hypothesis that compliance with a prescription is related to a patient's feeling of identification with his general practitioner. Ninety-two per cent of the identifiers complied well with a prescription for an antimicrobial drug compared with under half of the non-identifiers. Both identification and compliance were better in practice $B$, with its personal list system, than in practice $\mathrm{A}$, which operated a combined list, but compliance was strongly associated with identification within each practice.

Patients were identifiers if they answered yes to the question "You saw Dr X, do you feel you know him well ?" This follows from the definition in the Oxford Dictionary of identify: "associate oneself with, regard oneself as sharing characteristic with." Doctors are often exhorted to know their patients; it may also be important for patients to know their doctors. The concept of identification is necessarily subjective, and of course identification may be achieved after one consultation or may fail to happen after 14 visits to the doctor (table $I$ ). There is no reason why a patient on a combined list should not think that he knows more than one doctor well. Nevertheless, while we would not claim that the type of list used was the only important difference between the two practices studied, we think that a personal list is likely to encourage identification. Our results suggest that identification is not just a cosy relationship with the doctor but may be important in encouraging compliance in primary medical care.

Our assessment of compliance was objective. The validity of a pill count was questioned by Gordis, ${ }^{7}$ but he quoted two studies in which the patients were warned in some way that their medicine taking was going to be assessed. ${ }^{8}{ }^{9}$ In this study the interviews were without prior warning and hence we think that the pill count was reliable.

We made no attempt to standardise the illnesses for which the prescriptions were given, and indeed the two practices may have had very different prescribing policies. This was probably not important since the patients' perceived severity of illness was not significantly associated with compliance and the association between identification and compliance held within each practice. Other factors such as whether the patient stayed indoors were only weakly associated with better compliance in this study. Quite possibly some of these other variables would prove more relevant with longer-term drug treatment or particular conditions.

Compliance is not, of course, an end in itself and we did not attempt to assess the effectiveness of the treatments prescribed. It has been suggested that by not complying patients are protecting themselves from drug toxicity. ${ }^{10}$ Nevertheless, attempts to improve the quality, relevance, and effectiveness of prescribing will be hampered if we take too cynical a view of compliance; surely we must aim at appropriate prescribing with good compliance. It is sometimes suggested that patients take shortterm antibiotic treatment only while they still have symptoms. These results suggest that identification of the patient with his doctor may be a greater influence on compliance than symptomatic improvement.

If the patient's identification with his doctor proves to be an important factor in ensuring the effectiveness of treatment then there are at least two implications for general practice in Britain. Firstly, we need to modify our interviewing skills to improve identification, particularly for new patients. A recent review ${ }^{11}$ emphasised the importance of friendliness and conversing about non-medical matters, and this would seem an obvious way to help our patients to know us well. Such strategies are time consuming even if they pay off, and it is difficult to spend more time with patients in the face of inexorable demand for appointments. Secondly, a change in practice organisation may be needed. A personal list is one method of reducing the number of consultations with new patients. Gray found that as he saw a greater proportion of his own patients he dealt with more chronic illness and problems with relationships at the expense of minor self-limiting conditions. He believed that this meant improved quality of care. Our results suggest that a personal list might also lead to better compliance with short-term antibiotic prescriptions. More important, however, is compliance with long-term medication for conditions without symptoms, especially hypertension. Can we confirm that the identification of a hypertensive patient with his doctor is a potent factor in helping his compliance?

We gratefully acknowledge the help of the receptionists at Aldermoor and Shirley Health Centres in finding the patients for this study, and the constructive criticism from Dr Nigel Stott and $\mathrm{Dr}$ Malcolm Aylett. We thank Mrs Jean Gibson for typing the manuscript. 
Requests for reprints should be sent to Dr G K Freeman, Primary Medical Care, Aldermoor Health Centre, Aldermoor Close, Southampton SO1 6ST.

\section{References}

${ }^{1}$ Fox TF. The personal doctor. Lancet 1960;i:743-60.

${ }^{2}$ Anonymous. The educational needs of the future general practitioner. $\mathcal{F}$ Coll Gen Pract 1969;18:358-60.

3 Aylett MJ. Seeing the same doctor. $\mathcal{F} R$ Coll Gen Pract $1976 ; 26: 47-52$.

4 Gray DJP. The key to personal care. $\mathcal{F} R$ Coll Gen Pract 1979;29:666-78.

${ }^{5}$ Charney E, Bynam R, Eldridge D, et al. How well do patients take oral penicillin ? Pediatrics $1967 ; 40: 188-95$.

${ }^{6}$ Haynes RB. A critical review of the "determinants" of patient compliance with therapeutic regimens. In: Sackett DL, Haynes RB, eds. Compliance with therapeutic regimens. Baltimore: Johns Hopkins University Press, 1976 ;26-39.

${ }^{7}$ Gordis L. Methodologic issues in the measurement of patient compliance. In: Sackett DL, Haynes RB, eds. Compliance with therapeutic regimens. Baltimore: Johns Hopkins University Press, 1976;51-66.

${ }^{8}$ Bergman $\mathrm{AB}$, Wesner RJ. Failure of children to receive penicillin by mouth. $N$ Englf Med 1963;268:1334-8.

${ }^{9}$ Roth HP, Caron HS, Hsi BP. Measuring intake of a prescribed medication: a bottle count and a tracer technique compared. Clin Pharmacol Ther $1970 ; 11: 228-37$.

10 Anonymous. Non-compliance : does it matter ? Br Med f 1979 ;ii:1168.

${ }^{11}$ Sanson-Fisher R, Maguire P. Should skills in communicating with patients be taught in medical schools? Lancet 1980 ;ii :523-6.

(Accepted 11 February 1981)

\title{
Effect of radiocontrast media on kidneys of patients with renal disease
}

\author{
A RAHIMI， R P S EDMONDSON, N F JONES
}

\begin{abstract}
A prospective study was undertaken of 15 patients with impaired renal function undergoing $x$-ray procedures entailing the use of contrast material to see whether any deterioration in renal function resulted. Patients with diabetes or myelomatosis were excluded. Detailed observations were made during three days before and after the $x$-ray procedure to detect any change in factors such as fluid state, drug treatment, infection, or diet which might have affected renal function.

No significant changes occurred in endogenous creatinine and ${ }^{51} \mathrm{Cr}$-EDTA clearances, or in plasma creatinine and urea concentrations after the $x$-ray procedures. Furthermore, there was no change in urinary activity of N-acetyl-beta-D-glucosaminidase, which is a highly sensitive indicator of renal parenchymal damage.

Provided that fluid depletion and multiple $x$-ray procedures with radiocontrast material in rapid sequence are avoided, these procedures do not appear to affect renal function adversely, even when renal disease is advanced.
\end{abstract}

\section{Introduction}

The introduction of safer contrast materials and their use in larger doses have greatly increased the value of intravenous urography in patients with reduced renal function. High-dose urography is widely used in such patients and is generally considered to be safe provided that dehydration is avoided. ${ }^{1}$ Acute deterioration in renal function after urography may occur in patients with myelomatosis, but other factors such as hypercalcaemia and volume depletion are probably important. ${ }^{2}$ Deterioration in renal function after urography has also been reported in diabetic patients, chiefly with vascular disease and pre-existing renal impairment. ${ }^{3-6}$ Acute renal failure has also been recorded after angiography, computed tomography, and

Renal Laboratory, St Thomas's Hospital, London SE1 7EH A RAHIMI, MD, research fellow

R P S EDMONDSON, MD, MRCP, senior registrar

N F JONES, MD, FRCP, consultant physician cholecystography. ${ }^{7}$ With the above exceptions, early reports found little evidence that pre-existing renal disease by itself was a risk factor for urography. ${ }^{8-10}$ Later work, however, suggested that impaired renal function predisposed to radiocontrast-induced acute renal failure. ${ }^{711} 12$ If true, such reports raise the possibility that further renal damage may result from urography more commonly than is believed but may not be detected easily in the complex and unstable clinical state often present in patients with renal failure undergoing $x$-ray procedures. Moreover, the serum creatinine concentration-which is used in most published studies to monitor renal functionmay be an unsatisfactory guide to small but important changes in renal function. ${ }^{13}$

We have studied renal function prospectively before and after high-dose urography or angiography in patients with chronic renal failure, taking great care to monitor all other factors that might affect renal function during the period of the radiological investigation. In addition to measuring urea and creatinine concentrations we assessed glomerular filtration rate by the clearance of ${ }^{51} \mathrm{Cr}$-EDTA and measured urinary $\mathrm{N}$ acetyl- $\beta$-D-glucosaminidase (NAG) activity as a sensitive index of tubular damage.

\section{Patients and method}

We studied 15 patients (eight women, seven men) aged 25-70 years with varying degrees of renal failure. The underlying renal diseases (see table) were glomerulonephritis (eight patients), hypertensive nephrosclerosis (two), obstructive uropathy (two), analgesic nephropathy (one), chronic pyelonephritis (one), and scleroderma (one). High-dose intravenous urography was performed in 14 cases and selective renal angiography in one. Each patient was carefully assessed before and after the radiological study for any other factor which might have influenced renal function during this period. Particular attention was paid to fluid state including daily clinical assessment with recording of body weight, jugular venous and arterial pressures, fluid intake, and urine volume for at least three days before and after the investigation. Drugs, infections in the urinary tract or elsewhere, and changes in dietary intake were also recorded. We excluded patients in whom changes of possible significance in any of these factors occurred during the period of observation.

Fluid restriction and laxatives were carefully avoided in preparation for the $x$-ray procedure. For each high-dose intravenous urogram a single intravenous injection of $150 \mathrm{ml}$ Conray 420 was used; $60 \mathrm{ml}$ was given for the arteriogram.

During the three days before radiography blood urea and plasma 